\title{
Coordination of Supply Chain under the Revenue Sharing-Advertising Cost Sharing Contract
}

\author{
Meng Jia \\ Management School, Jinan University, Guangzhou, China \\ Email: 402768736@qq.com
}

How to cite this paper: Jia, M. (2017) Coordination of Supply Chain under the Revenue Sharing-Advertising Cost Sharing Contract. Journal of Service Science and Management, 10, 309-318.

https://doi.org/10.4236/jssm.2017.103024

Received: May 12, 2017

Accepted: June 20, 2017

Published: June 23, 2017

Copyright $\odot 2017$ by author and Scientific Research Publishing Inc. This work is licensed under the Creative Commons Attribution International License (CC BY 4.0).

http://creativecommons.org/licenses/by/4.0/ (c) (i) Open Access

\begin{abstract}
In this article, we study a two-echelon supply chain with a single manufacturer and a single retailer. In the case of advertising investment affecting the market demand, we use the theory of game theory, and respectively discuss the coordination of general revenue sharing contract and revenue sharingadvertising cost sharing contract. The results show that: the general revenue sharing contract cannot achieve supply chain coordination. However, revenue sharing-advertising cost sharing contract in a specific form can achieve supply chain coordination. And in the appropriate revenue sharing contract parameters, it can also achieve a win-win situation between the two sides.
\end{abstract}

\section{Keywords}

Supply Chain Coordination, Revenue Sharing Contract, Advertising Investment, Cost Sharing

\section{Introduction}

The revenue sharing contract, which coordinates the cooperation among supply chain members, has become one of the important directions of supply chain management research. The revenue sharing contract refers to the manufacturer and the retailer through negotiation; the manufacturer sets a lower wholesale price for selling the products to the retailer, then the retailer will share the sales revenue to the manufacturer according to the predetermined proportion after the completion of the sale. The revenue sharing contract is helpful to realize the coordination and the whole optimization of supply chain members. The successful application of revenue sharing contracts in the CD industry in the USA has attracted more and more scholars' attention to revenue sharing contracts. Mortimer (2000) makes an empirical study on the recording rental industry. The 
results show that the revenue sharing contract can increase the profit of the node enterprises in the supply chain by $3 \%-6 \%$ [1]. The study of revenue sharing contract is no longer limited to descriptive research, but extended to the general supply chain for more theoretical research. Cachon (2001) first studied the revenue sharing contract using mathematical modeling, and thought that revenue sharing contract was an improvement to the wholesale price contract, and it could coordinate the supply chain more effectively [2]. In recent years, more and more researches about the revenue sharing contract have proved that the revenue sharing contract can realize coordination of supply chain [3]-[8]. However, most of these researches don't consider the simultaneous influence of retailers' advertising and price on demand. In practice, advertising, as an effective and common marketing tool, can provide consumers with purchasing information, and can increase product brand effect, stimulate consumer purchasing behavior and tap potential consumers [9]. Therefore, as advertising investment is an important factor of affecting demand, it is necessary to consider advertising investment in the study.

Here the paper considers the case of the retailer's advertising investment, establishes an effective revenue sharing contract, realizes the supply chain coordination, and makes optimal advertising cost and optimal price.

The paper proceeds as follows: the next section presents the assumptions and the basic symbol definitions. Then three models are discussed. One is a cooperative relationship model, next is a general revenue sharing contract model, and the last one is a revenue sharing-advertising cost sharing contract model. The main results are analyzed and compared, followed by the discussion of contractual conditions problem. Finally, the conclusion summarizes the findings.

\section{Assumptions and the Basic Symbol Definitions}

In order to facilitate the modeling and analysis, we consider a two-echelon supply chain with a single manufacturer (M) and a single retailer (R). In the supply chain, the manufacturer produces the products, then the retailer purchases them, and the retailer sells to consumers. Assume that both the manufacturer and the retailer are risk neutral, and the information between them is completely symmetric. The retailer is advertising to influence market demand and then determines the amount of products ordered. The manufacturer produces the product according to the retailer's order requirements. Assume that the manufacturer's capacity meets the retailer's order requirements, so there is the quantity demanded equal to the production output.

The basic symbol definitions as follows:

$w$, he manufacturer's wholesale price;

$c$, the manufacturer's unit production cost, $c>0$;

$p$, the retailer's retail price;

$a$, the retailer's advertising cost;

$t$, the manufacturer's participation rate, $0 \leq t \leq 1$;

$k$, the efficacy of the retailer's advertising in generating sales, $k>0$; 
$\alpha$, the sales saturate asymptote, $\alpha>0$;

$\beta$, the efficacy of the retailer's retail price in generating sales, $\beta>0$;

$\lambda$, the retailer's revenue sharing ratio, $0 \leq \lambda \leq 1$

The paper assumes that the quantity demanded is influenced by the retailer's retail price and advertising cost [10] [11]. Setting the demand function [12] as $D=(\alpha-\beta p) k \sqrt{a}$, in order to ensure $q>0$, we need to restrict $0<p<\frac{\alpha}{\beta}$.

The profits of the manufacturer, the retailer and the system are as follows, respectively:

$$
\begin{gathered}
\pi_{m}=(w-c)(\alpha-\beta p) k \sqrt{a}-t a \\
\pi_{r}=(p-w)(\alpha-\beta p) k \sqrt{a}-(1-t) a \\
\pi_{m+r}=(p-c)(\alpha-\beta p) k \sqrt{a}-a
\end{gathered}
$$

\section{The Cooperative Relationship Model}

In this section, we focus on a cooperative game structure in which both the manufacturer and the retailer agree to make decisions that maximize the total channel profits (joint profit maximization).

The system profits are described by Equation (3) and depend only on p and a. We hence have the following optimization problem:

$$
\max \pi_{m+r}=(p-c)(\alpha-\beta p) k \sqrt{a}-a
$$

This problem can easily be solved by equating the two partial derivatives to zero. Specifically, by taking $\frac{\partial_{\pi_{m+r}}}{\partial_{p}}=0$ and $\frac{\partial_{\pi_{m+r}}}{\partial_{a}}=0$, we have the unique solution expressed as

$$
\begin{gathered}
p^{C^{*}}=\frac{\alpha+\beta c}{2 \beta} \\
a^{C^{*}}=\frac{k^{2}(\alpha-\beta c)^{4}}{64 \beta^{2}}
\end{gathered}
$$

Therefore, the optimal profits for the whole system can be calculated as

$$
\pi_{m+r}^{C^{*}}=\frac{k^{2}(\alpha-\beta c)^{4}}{64 \beta^{2}}
$$

The supply chain coordination is to make the optimal solution of each member of supply chain consistent with the decision under the centralized supply chain, and maximize the total channel profits. Therefore, Equation (4) and Equation (5) are necessary conditions to achieve the supply chain coordination.

\section{The General Revenue Sharing Contract Model}

In this section, the retailer determines the amount of products ordered according to the market demand, and then purchases products at a lower wholesale price from the manufacturer. After the completion of the sale, the retailer will share the sales revenue to the manufacturer according to $1-\lambda$ the predeter- 
mined proportion. We model the relationship between the manufacturer and the retailer, with the manufacturer as the leader and the retailer as the follower. The solution of this leader-follower game is called the Stackelberg manufacturer equilibrium. In order to determine the Stackelberg equilibrium by backward induction, we first solve the retailer's optimal problem when the manufacturer's decision variables $w$ and $\lambda$ are given:

$$
\max \pi_{r}=(\lambda p-w)(\alpha-\beta p) k \sqrt{a}-a
$$

Since $\pi_{r}$ is a concave function with respect to $p$ and $a$, we can solve the two first order equations $\frac{\partial_{\pi_{r}}}{\partial_{p}}=0$ and $\frac{\partial_{\pi_{r}}}{\partial_{a}}=0$ to get the optimal values:

$$
\begin{gathered}
p^{S N^{*}}=\frac{\alpha \lambda+\beta w}{2 \beta \lambda} \\
a^{S N^{*}}=\frac{k^{2}(\alpha \lambda-\beta w)^{4}}{64 \lambda^{2} \beta^{2}}
\end{gathered}
$$

Next, the optimal values of $w$ and $\lambda$ are determined by maximizing the manufacturer's optimal problem subject to the constraints imposed by Equation (6) and Equation (7). That is,

$$
\max \pi_{m}=[(1-\lambda) p+w-c](\alpha-\beta p) k \sqrt{a}
$$

Substituting Equation (6) and Equation (7) into the expression of $\pi_{m}$, then by taking $\frac{\partial \pi_{m}}{\partial w}=0$ and $\frac{\partial \pi_{m}}{\partial \lambda}=0$, we have

$$
\begin{gathered}
w^{S N^{*}}=\frac{6 \beta c-\alpha}{15 \beta} \\
\lambda^{S N^{*}}=\frac{1}{3}
\end{gathered}
$$

Substituting Equation (8) and Equation (9) into the expression of $p$ and $a$, we have

$$
\begin{gathered}
p^{S N^{*}}=\frac{2 \alpha+3 \beta c}{5 \beta} \\
a^{S N^{*}}=\frac{9 k^{2}(\alpha-\beta c)^{4}}{2500 \beta^{2}}
\end{gathered}
$$

Hence, the optimal profits of the manufacturer, the retailer and the system are as follows, respectively:

$$
\begin{aligned}
& \pi_{m}^{S N^{*}}=\frac{9 k^{2}(\alpha-\beta c)^{4}}{1250 \beta^{2}} \\
& \pi_{r}^{S N^{*}}=\frac{9 k^{2}(\alpha-\beta c)^{4}}{2500 \beta^{2}} \\
& \pi_{m+r}^{S N^{*}}=\frac{27 k^{2}(\alpha-\beta c)^{4}}{2500 \beta^{2}}
\end{aligned}
$$




\section{Proposition 1}

When the manufacturer don't share the retailer's advertising costs, the general revenue sharing contract can't achieve supply chain coordination.

Proof of Proposition 1.

Equation (4) and Equation (5) are necessary conditions to achieve the supply chain coordination. So we will compare $p^{C^{*}}$ and $p^{S N^{*}}, a^{C^{*}}$ and $a^{S N^{*}}$. The results are $\frac{\alpha+\beta c}{2 \beta}>\frac{2 \alpha+3 \beta c}{5 \beta}$ and $\frac{k^{2}(\alpha-\beta c)^{4}}{64 \beta^{2}}>\frac{9 k^{2}(\alpha-\beta c)^{4}}{2500 \beta^{2}}$. Then in this paper we have $p^{C^{*}}>p^{S N^{*}}$ and $a^{C^{*}}>a^{S N^{*}}$. Thus the manufacturer don't share the retailer's advertising costs, the general revenue sharing contract can't achieve supply chain coordination.

In the general revenue sharing contract model, the retailer alone undertakes the advertising costs in the supply chain, but it only gains a portion of the profits of the supply chain system. Therefore, the retailer's advertising cost must be lower than the optimal advertising cost of the cooperative relationship model. In order to reduce the pressure of the retailer's advertising investment and increase the retailer's advertising cost, this paper then considers a revenue sharing contract based on advertising cost sharing.

\section{The Revenue Sharing-Advertising cost Sharing Contract Model}

\subsection{The Analyses of the Model}

In this section, the retailer determines the amount of products ordered according to the market demand, and then purchases products at a lower wholesale price from the manufacturer. And the manufacturer agrees to pay the retailer to subsidize the advertising cost ( $t$ the manufacturer's participation rate). After the completion of the sale, the retailer will share the sales revenue to the manufacturer according to $1-\lambda$ the predetermined proportion. We model the relationship between the manufacturer and the retailer, with the manufacturer as the leader and the retailer as the follower. The solution of this leader-follower game is called the Stackelberg manufacturer equilibrium. In order to determine the Stackelberg equilibrium by backward induction, we first solve the retailer's optimal problem when the manufacturer's decision variables $\mathrm{w}$ and $\mathrm{t}$ are given:

$$
\max \pi_{r}=(\lambda p-w)(\alpha-\beta p) k \sqrt{a}-(1-t) a
$$

The purpose of the revenue sharing-advertising cost sharing contract is to achieve supply chain coordination. Equation (4) and Equation (5) are necessary conditions to achieve the supply chain coordination. So in the model, we make the retailer's optimal retail price and advertising cost equal to the optimal solution of the cooperative relationship model. That is $p^{S Y^{*}}=p^{C^{*}}$ and $a^{S Y^{*}}=a^{C^{*}}$.

Since $\pi_{r}$ is a concave function with respect to $p$ and $a$, we can solve the two first order equations $\frac{\partial \pi_{r}}{\partial p}=0$ and $\frac{\partial \pi_{r}}{\partial a}=0$ to get the optimal values: 


$$
\begin{gathered}
p^{S Y^{*}}=\frac{\alpha \lambda+\beta w}{2 \beta \lambda} \\
a^{S N^{*}}=\frac{k^{2}(\alpha \lambda-\beta w)^{4}}{64(1-t)^{2} \lambda^{2} \beta^{2}}
\end{gathered}
$$

When $p^{S Y^{*}}=p^{C^{*}}$, we have $\frac{\alpha \lambda+\beta w}{2 \beta \lambda}=\frac{\alpha+\beta c}{2 \beta}$.

Therefore, we can calculate $\mathrm{w}$ as

$$
w=\lambda c
$$

Equation (10) shows that in the revenue sharing-advertising cost sharing contract model, the manufacturer's wholesale price $\left(w^{*}\right)$ is equal to $\lambda c$.

\section{Proposition 2}

In the revenue sharing-advertising cost sharing contract model, the retailer's revenue sharing ratio has an impact on the wholesale price, and there is a direct proportion between them.

Proof of Proposition 2.

This problem can be easily solved by the partial derivatives of Equation (10), then $\frac{\partial w}{\partial \lambda}=c$. Because of $c>0$, there is a direct proportion between $w$ and $c$. As the retailer's revenue sharing ratio increases, the manufacturer must raise its wholesale price in order to compensate for its losses. It can be seen that if the retailer don't make concessions on its revenue sharing ratio, it will not get the desired wholesale price.

Substituting Equation (10) into the expression of $a$, we have

$$
a^{S N^{*}}=\frac{k^{2}(\alpha-\beta c)^{4} \lambda^{2}}{64(1-t)^{2} \beta^{2}}
$$

When $a^{S Y^{*}}=a^{c^{*}}$, we have $\frac{k^{2}(\alpha-\beta c)^{4} \lambda^{2}}{64(1-t)^{2} \beta^{2}}=\frac{k^{2}(\alpha-\beta c)^{4}}{64 \beta^{2}}$.

Therefore, we can calculate $t$ as

$$
t=1-\lambda
$$

\section{Proposition 3}

In the revenue sharing-advertising cost sharing contract model, the retailer's revenue sharing ratio has an impact on the manufacturer's participation rate, and the manufacturer's participation rate decreases monotonically with the retailer's revenue sharing ratio increasing.

Proof of Proposition 3.

This problem can be easily solved by the partial derivatives of Equation (11), then $\frac{\partial w}{\partial \lambda}=c$. Because of $-1>0, t$ decreases monotonically with $\lambda$ increasing. As the retailer's revenue sharing ratio increases, the manufacturer must reduce its participation rate in order to compensate for its losses. It can be seen that if the retailer don't make concessions on its revenue sharing ratio, it will not get the desired wholesale price. On the contrary, in order to achieve higher sales 
revenue return, the manufacturer will undertake higher proportion of the retailers' advertising costs.

Hence, the optimal profits of the manufacturer, the retailer and the system are as follows, respectively:

$$
\begin{gathered}
\pi_{m}^{S Y^{*}}=\frac{k^{2}(\alpha-\beta c)^{4}(2-2 \lambda-t)}{64 \beta^{2}} \\
\pi_{r}^{S Y^{*}}=\frac{k^{2}(\alpha-\beta c)^{4}(2 \lambda+t-1)}{64 \beta^{2}} \\
\pi_{m+r}^{S Y^{*}}=\frac{k^{2}(\alpha-\beta c)^{4}}{64 \beta^{2}}
\end{gathered}
$$

\section{Proposition 4}

In the revenue sharing-advertising cost sharing contract model, when $w=\lambda c$ and $t=1-\lambda$, the optimal total channel profits of the model is equal to the optimal total channel profits of the cooperative relationship model. The revenue sharing-advertising cost sharing contract can achieve supply chain coordination.

Proof of Proposition 4.

Analyze the results of the model, we have the following observations. When $w=\lambda c$ and $t=1-\lambda$, we can get the results of the model, $p^{s Y^{*}}=\frac{\alpha+\beta c}{2 \beta}$ and $a^{S Y^{*}}=\frac{k^{2}(\alpha-\beta c)^{4}}{64 \beta^{2}}$. So we will compare $p^{C^{*}}$ and $p^{S Y^{*}}, a^{C^{*}}$ and $a^{S Y^{*}}$. The results are $p^{S Y^{*}}=p^{C^{*}}$ and $a^{S Y^{*}}=a^{C^{*}}$. Here, the revenue sharing-advertising cost sharing contract can achieve supply chain coordination.

\subsection{The Contractual Conditions of the Model}

According to the Pareto optimization principle of the supply chain, if the members accept revenue sharing-advertising cost sharing contract, they must meet the individual rational constraints. Hence we will consider the relationship between the manufacturer and the retailer as a sequential non-cooperative game, where the manufacturer is the leader and the retailer is the follower. The solution of this leader-follower game is called the Stackelberg manufacturer equilibrium. In order to determine the Stackelberg equilibrium by backward induction, we first solve the retailer's optimal problem when the manufacturer's decision variables $\mathrm{w}$ and $\mathrm{t}$ are given:

$$
\max \pi_{r}=(p-w)(\alpha-\beta p) k \sqrt{a}-(1-t) a
$$

Since $\pi_{r}$ is a concave function with respect to $p$ and $a$, we can solve the two first order equations $\frac{\partial \pi_{r}}{\partial p}=0$ and $\frac{\partial \pi_{r}}{\partial a}=0$ to get the optimal values:

$$
p^{s^{*}}=\frac{\alpha+\beta w}{2 \beta}
$$




$$
a^{s^{*}}=\frac{k^{2}(\alpha-\beta w)^{4}}{64(1-t)^{2} \beta^{2}}
$$

Next, the optimal values of $w$ and $t$ are determined by maximizing the manufacturer's optimal problem subject to the constraints imposed by Equation (12) and Equation (13). That is,

$$
\max \pi_{m}=(w-c)(\alpha-\beta p) k \sqrt{a}-t a
$$

Substituting Equation (12) and Equation (13) into the expression of $\pi_{m}$, then by taking $\frac{\partial \pi_{m}}{\partial w}=0$ and $\frac{\partial \pi_{m}}{\partial \lambda}=0$, we have

$$
\begin{gathered}
w^{s^{*}}=\frac{\alpha+2 \beta c}{3 \beta} \\
t^{s^{*}}=\frac{1}{3}
\end{gathered}
$$

Substituting Equation (14) and Equation (15) into the expression of $p$ and $a$, we have

$$
\begin{gathered}
p^{s^{*}}=\frac{2 \alpha+\beta c}{3 \beta} \\
a^{s^{*}}=\frac{k^{2}(\alpha-\beta c)^{4}}{144 \beta^{2}}
\end{gathered}
$$

Hence, the optimal profits of the manufacturer, the retailer are as follows, respectively:

$$
\begin{aligned}
& \pi_{m}^{S^{*}}=\frac{k^{2}(\alpha-\beta c)^{4}}{144 \beta^{2}} \\
& \pi_{r}^{S^{*}}=\frac{k^{2}(\alpha-\beta c)^{4}}{216 \beta^{2}}
\end{aligned}
$$

If the members accept revenue sharing-advertising cost sharing contract, they must meet the individual rational constraints. That is $\pi_{m}^{S Y^{*}} \geq \pi_{m}^{S^{*}}$ and $\pi_{r}^{S Y^{*}} \geq \pi_{r}^{S^{*}}$.

Hence, we have

$$
\begin{aligned}
& \frac{k^{2}(\alpha-\beta c)^{4}(2 \lambda+t-1)}{64 \beta^{2}} \geq \frac{k^{2}(\alpha-\beta c)^{4}}{144 \beta^{2}} \\
& \frac{k^{2}(\alpha-\beta c)^{4}(2 \lambda+t-1)}{64 \beta^{2}} \geq \frac{k^{2}(\alpha-\beta c)^{4}}{216 \beta^{2}}
\end{aligned}
$$

Because of Equation (11), we can calculate the range of $\lambda$

$$
\frac{8}{27} \leq \lambda \leq \frac{5}{9}
$$

Hence, the range of the optimal profits of the manufacturer and the retailer are as follows, respectively:

$$
\pi_{m}^{S Y} \in\left[\frac{k^{2}(\alpha-\beta c)^{4}}{144 \beta^{2}}, \frac{19 k^{2}(\alpha-\beta c)^{4}}{378 \beta^{2}}\right]
$$




$$
\pi_{r}^{S Y} \in\left[\frac{k^{2}(\alpha-\beta c)^{4}}{216 \beta^{2}}, \frac{5 k^{2}(\alpha-\beta c)^{4}}{576 \beta^{2}}\right]
$$

\section{Proposition 5}

In the revenue sharing-advertising cost sharing contract model, when $w=\lambda c$ and $t=1-\lambda$, it can achieve supply chain coordination. And then when $\frac{8}{27} \leq \lambda \leq \frac{5}{9}$, the members accept the contract, the form of the contract is valid, otherwise the contract form is invalid.

Proof of Proposition 5.

Analyze the contractual conditions of the model, we have the following observations. From proposition 4, we know that when $w=\lambda c$ and $t=1-\lambda$, the revenue sharing-advertising cost sharing contract can achieve supply chain coordination. And then when $\frac{8}{27} \leq \lambda \leq \frac{5}{9}$, we can compare $\pi_{m}^{S Y^{*}}$ and $\pi_{m}^{S^{*}}, \pi_{r}^{S Y^{*}}$ and $\pi_{r}^{S^{*}}$. The results are $\pi_{m}^{S Y^{*}} \geq \pi_{m}^{S^{*}}$ and $\pi_{r}^{S Y^{*}} \geq \pi_{r}^{S^{*}}$. So the members meet the individual rational constraints, and then they wilk accept revenue sharing-advertising cost sharing contract.

\section{Concluding Remarks}

This paper analyzes pricing, advertising and coordination problems of the supply chain with a single manufacturer and a single retailer. The results show that when the manufacturer doesn't share the retailer's advertising costs, the general revenue sharing contract can't achieve supply chain coordination. In the revenue sharing-advertising cost sharing contract model, when $w=\lambda c$ and $t=1-\lambda$, the optimal total channel profits of the model are equal to the optimal total channel profits of the cooperative relationship model. And then when $\frac{8}{27} \leq \lambda \leq \frac{5}{9}$, the manufacturer and the retailer meet the individual rational constraints and accept the contract. Thus the revenue sharing-advertising cost sharing contract in the specific form can achieve supply chain coordination.

Our study makes the following contributions to the channel coordination literature:

1) We add to the scanty literature of game theoretical models that simultaneously optimize pricing and advertising decisions.

2) Most previous studies don't consider the coordination instrument with pricing and advertising. We find that when pricing and advertising are considered simultaneously, in the specific form $\frac{8}{27} \leq \lambda \leq \frac{5}{9}$, the revenue sharingadvertising cost sharing contract can achieve supply chain coordination.

Our model has some limitations. First, we use the linear demand-price function. As Choi (1991) has found, different demand-price functions may yield significantly different results and implications. Second, we only consider a twoechelon supply chain with a single manufacturer and a single retailer. Besides, we only consider the retailer's advertising costs, but don't consider the manu- 
facturer's advertising costs. In the future, we can extend the channel structure to settings with multiple retailers or multiple manufacturers and explore the dimensions of channel studies such as price competition and product differentiation.

\section{References}

[1] Mortime, J.H. (2000) The Effects of Revenue-Sharing Contracts on Welfare in Vertically-Separated Markets: Evidence from the Video Rental Industry. Harvard Institute of Economic Research, 202, 1-49.

[2] Cachon, G.P. and Lariviere M.A. (2000) Contracting to Assure Supply: How to Share Demand Forecasts in a Supply Chain. Management Science, 47, 629-646. https://doi.org/10.1287/mnsc.47.5.629.10486

[3] Lau, A.H.L and Lau, H.S. (2002) The Effects of Reducing Demand Uncertainty in a Manufacturer-Retailer Channel for Single-Period Products. Computers \& Operations Research, 29, 1583-1602. https://doi.org/10.1016/S0305-0548(01)00047-8

[4] Cachon, G.P. and Lariviere M.A. (2005) Supply Chain Coordination with Revenue-Sharing Contracts: Strengths and Limitations. Management Science, 51, 30-44. https://doi.org/10.1287/mnsc.1040.0215

[5] Palsule-Desai, O.D. (2013) Supply chain Coordination Using Revenue-Dependent Revenue Sharing Contracts. Omega, 41, 780-796.

https://doi.org/10.1016/j.omega.2012.10.001

[6] Gerchak, Y. and Wang, Y.Z. (2008) Revenue-Sharing vs. Wholesale-Price Contracts in Assembly Systems with Random Demand. Production and Operations Management, 13, 23-33. https://doi.org/10.1111/j.1937-5956.2004.tb00142.x

[7] Berger, P.D. (1973) Statistical Decision Analysis of Cooperative Advertising Ventures. Journal of the Operational Research Society, 24, 207-216.

https://doi.org/10.1057/jors.1973.38

[8] Dant, R.P and Berger, P.D. (1996) Modelling Cooperative Advertising Decisions in Franchising. Journal of the Operational Research Society, 47, 1120-1136. https://doi.org/10.1057/jors.1996.141

[9] Huang, Z. and Li, S.X. (2001) Co-Op Advertising Models in Manufacturer-Retailer Supply Chains: A Game Theory Approach. European Journal of Operational Research, 135, 527-544. https://doi.org/10.1016/S0377-2217(00)00327-1

[10] Xie, J. and Wei, J.C. (2009) Coordinating Advertising and Pricing in a Manufacturer-Retailer Channel. European Journal of Operational Research, 197, 785-791. https://doi.org/10.1016/j.ejor.2008.07.014

[11] Xie, J. and Neyret, A. (2009) Co-Op Advertising and Pricing Models in Manufacturer-Retailer Supply Chains. Computers \& Industrial Engineering, 56, 1375-1385. https://doi.org/10.1016/j.cie.2008.08.017

[12] Aust, G. and Buscher, U. (2012) Vertical Cooperative Advertising and Pricing Decisions in a Manufacturer-Retailer Supply Chain: A Game-Theoretic Approach. European Journal of Operational Research, 223, 473-482. https://doi.org/10.1016/j.ejor.2012.06.042 
Submit or recommend next manuscript to SCIRP and we will provide best service for you:

Accepting pre-submission inquiries through Email, Facebook, LinkedIn, Twitter, etc. A wide selection of journals (inclusive of 9 subjects, more than 200 journals)

Providing 24-hour high-quality service

User-friendly online submission system

Fair and swift peer-review system

Efficient typesetting and proofreading procedure

Display of the result of downloads and visits, as well as the number of cited articles Maximum dissemination of your research work

Submit your manuscript at: http://papersubmission.scirp.org/

Or contact jssm@scirp.org 